THE CANADIAN JOURNAL OF AUTISM EQUITY LA REVUE CANADIENNE DE L'ÉQUITÉ EN MATIÈRE D'AUTISME VOLUME 1 ISSUE 1 APRIL 2021

\title{
Supporting Autistic Culture in Defining Autistic Identity
}

Gerald Beaulieu, Independent Researcher, Canada 


\title{
Supporting Autistic Culture in Defining Autistic Identity
}

\author{
Gerald Beaulieu1
}

\begin{abstract}
Late diagnosed Autistic adults who are also practicing artists are very likely to have clues about their identities expressed in their work. This gives them the opportunity to reevaluate their meaning through a more accurate lens and proper context. It also challenges viewers and audiences to do the same and to confront misconceptions. These biases are likely to extend across all forms of cultural production. This leaves Autistic and disabled artists with a very small and unrecognized footprint in our current cultural landscape. This needs to be rectified by rejecting outmoded stereotypes and establishing committed programs of engagement with Autistic culture by our public institutions. Résumé

Les adultes autistes qui ont reçu un diagnostic tardif et qui sont également des artistes actifs sont très susceptibles de trouver, dans leurs œuvres, des indices de leur identité. Cela leur donne l'occasion de réévaluer la signification de leur travail à travers une optique plus précise et un contexte approprié. Cela incite également les spectateurs et le public à faire de même et à confronter leurs idées fausses. Ces préjugés sont susceptibles de s'étendre à toutes les formes de production culturelle. Les artistes autistes et handicapés n'ont donc qu'une empreinte très réduite et non reconnue dans notre paysage culturel actuel. Il est donc nécessaire de rectifier la situation en rejetant les vieux stéréotypes et en établissant dans nos institutions publiques des programmes d'engagement ciblés envers la culture autiste.
\end{abstract}

\author{
Keywords \\ Autism, Culture, Disability, Identity \\ Mots clés \\ Autisme, Culture, Handicap, Identité
}

1 Independent Researcher, Canada 
Late-diagnosed Autistic adults who are also practicing artists are very likely to have clues about their identities expressed in their work. This gives them the opportunity to reevaluate their meaning through a more accurate lens and proper context. It also challenges viewers and audiences to do the same and to confront their own misconceptions. These biases are likely to extend across all forms of cultural production. This leaves Autistic and disabled artists with a very small and unrecognized footprint in our current cultural landscape. This issue needs to be rectified by rejecting outmoded stereotypes and establishing committed programs of engagement with Autistic culture by our public institutions.

Once you make the discovery that you are Autistic after spending over half your life not knowing, it is common to review your life looking for clues and signs. When you have also made art your entire life, you look for that evidence in your work. Were there any red flags, anything obviously Autistic?

Normally, I don't do autobiographical work. I prefer broader social themes to personal narratives, so I was doubtful as to what I would find. However, in 1997 I decided to make a lifesized superhero figure, and eventually made a total of seven figures over the coming years. It was worth looking at these figures through a focused Autistic lens. What was the real story they were telling?

Now, there are lots of things to like about the superhero ethos; the action, capes, and near God-like powers. There is a reason they're popular and remain a mainstay of pop culture. My interest was different though - I was fascinated by the notion of maintaining a secret identity, of living a dual life. I wanted to strip away the disguise, render my heroes naked, and see what I would find. So that is what I did.

When you make art, at some point, you have to stop conceptualizing and start making; putting things together, working intuitively, trusting your emotions and senses to guide you. Carving my first figure, I gave him wings so he could fly. Posed him head down, arms folded, standing in quiet, patient resolve. Then, I set him on fire. If these works were to be truly autobiographical, then his state would not be of flight and soaring but of crashing and burning. Any heroism was in the resolve to keep getting up; to keep going, and to face the fate of being consumed by flames again.

Other figures were telling the same story - wrestling with the same plight, not to achieve any heroic feat, but struggling just to be. There were figures trapped in seized and rusted armour, turning themselves inside out, melting and crumbling in a state of disintegration and decay. There was no flight or fight; they were all frozen in their state of reveal. In hindsight, informed by a new awareness, what these works were revealing and exploring is the phenomena known as Autistic masking or camouflaging. This occurs when an Autistic person adapts their personality to 


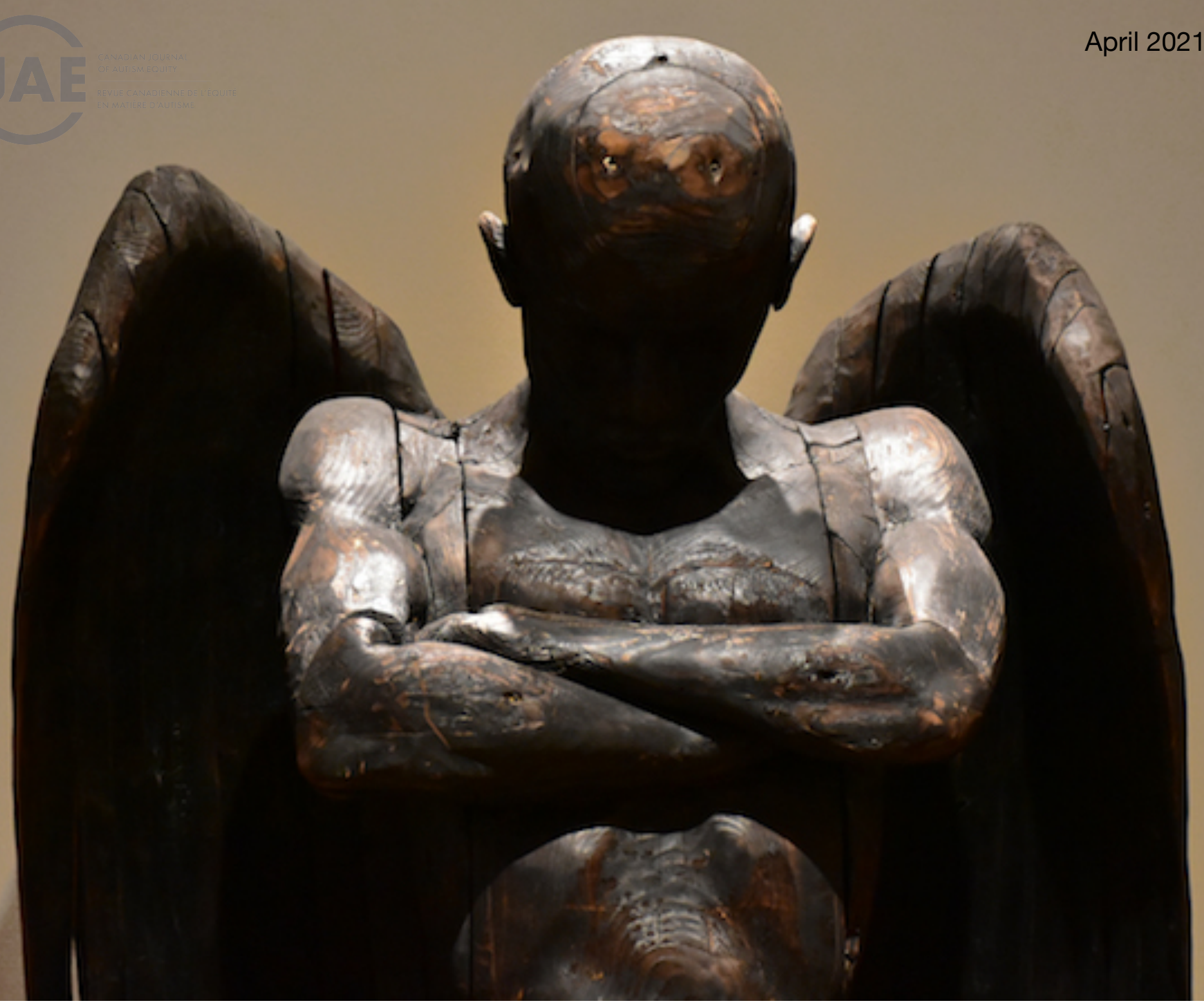

suppress their Autistic behaviours in an attempt to gain social acceptance (Hull et al., 2017). It is the act of creating an acceptable social persona so as to conceal one's actual personality. Because my greatest weakness wasn't Kryptonite; it was people finding out who I really was, revealing my true identity. I learned at an early age this is not what people wanted to see. I understood what stigma was and perfected my persona to avoid it. I was good at it. After all, I am an artist, and one thing I excel at is creating fictions.

In June of 2006, I finished the final works of this series at an artist residency at Gallery Connexion in Fredericton, New Brunswick. Residencies are interesting exercises, as they give you immediate audience feedback. My work was initially well received, but this success did not last long. All my attempts to show the works at other public galleries and art museums failed. At best, some curators were mildly amused. Most seemed to view the series as a misguided adventure into comic book fandom. When I made the work, I just assumed that everyone behaved the way I did that everyone carefully observed the world around them and meticulously constructed their public persona. Carefully scripting each interaction, refining and adjusting their presence, 
replaying each conversation, inventing and reinventing themselves. Wasn't this how everyone moved through the world? Weren't these feelings and experiences universal? When expressed, how did they miss their mark with my curatorial peers?

Of course, these pieces failed to connect. Without context there could be no real understanding. Everything I felt and experienced was concrete, but evaporated without comprehending its source, their origins, the back story. My otherness could not be properly understood if it was not correctly defined or in tune with expectations. My experiences had no point of reference in popular culture even though I was trying to use that culture as a medium for communicating them.

This is why we need Autistic voices to define who we are, and why we need Autistic voices to be heard. It is our voices that need to articulate our experiences, to become the principal authors of our stories rather than being a footnote to someone else's narrative about who we are. Through this sharing of our experiences and our culture, we can attain a greater understanding of our place in the world and how we can contribute to shaping its future. Looking for these authentic Autistic voices in the current cultural landscape is a disappointing experience. It should first be recognized that being an artist is hard and getting more difficult; having a disability will not ease that struggle. The British neurodivergent artist Anna Berry (2017) writes:

There is so much conversation in the art world about identity (arguably too much) race, gender, culture, sexuality - but we're still not on an equal footing in that discussion when the identity is one of disability. It's the poor relation of identity politics. Disability is not afforded anything like the same graceful acceptance, tact, and recognition about the need for representation in that discussion [...] disability is lagging way behind; roughly where other strands of identity politics were in the eighties, l'd argue. The sad reality is that it's still an identity you think twice about adopting if you want to be taken seriously in the art world (paras. 8-11).

This willingness to keep the invisible out of sight can be found lurking in institutional policies that appear to support diversity. Many arts organizations like funding agencies have user profiles to access client services. These profiles allow one to identify by gender, race, linguistic or cultural minority, with all the nuances associated with these identities. For disability, it is usually a check box with no specifics. These organizations portray disability as some unfortunate thing that happens to you. It is not something you're allowed to celebrate, but rather something you admit to having; a situation that ideally you would want to overcome if given the chance. The challenge of accommodating a population of creators with social deficits must seem too daunting to deal with in the current cultural ecosystem. It is easier to pretend the problem isn't there.

While tech companies like IBM have recruitment programs for neurodiverse talent and 
Forbes magazine writes frequently about the subject, it is embarrassing to say that neurodiversity is almost never discussed in terms of cultural policy. This is where the problem becomes systemic, because the main vector in the arts for opportunity and career advancement is social networking. It is built into every network and support system - it is a 'who you know' business.

As an artist, you need to do two things in order to be successful. You need to make good work, and you need to get noticed. Artists that never get noticed have really lousy careers. While getting noticed is good, getting noticed by the right people is better. This is where social networking comes in to play. This is how so much opportunity happens. This is how doors are opened, and how careers are made. This is also how Autistic artists are disabled by a system they cannot comprehend, let alone navigate. This is what having social deficits looks like, and you pay a steep price for being different.

It stands to reason that if Autistic creators can't succeed, then Autistic stories will not be told. We know the power of culture and the narratives that we construct, and we also know how important it is to see yourself reflected and participating in these narratives. We also know that succeeding in the arts is not easy to begin with. It is a tough career path with a high rate of failure. Marginalized communities often need assistance and conscious efforts at inclusion to take their stories out of the margins and into the mainstream.

The first steps are to stop making disability a dirty word. Then to recognize that neurodiversity exists, that Autistic artists are present and have something unique to say. To lift the shaming veil of invisibility and actively seek out Autistic artists. To connect these artists with audiences but on their own terms, with grace and acceptance.

It is a sad state of affairs to think that arguably the most recognized Autistic people are fictional characters created by non-autistic authors. This is our starting point in asking for equity in the twenty-first century. It is time for our cinemas, theatres, libraries and galleries to reflect who we are. It is time to embrace and recognize Autistic culture and to present the artistic endeavours of people who think differently.

\section{References}

Hull, L., Petrides, K. V., Allison, C., Smith, P., Baron-Cohen, S., Lai, M. C., \& Mandy, W. (2017). "Putting on My Best Normal": Social Camouflaging in Adults with Autism Spectrum Conditions. Journal of autism and developmental disorders, 47(8), 2519-2534. https://doi.org/10.1007/s10803-017-3166-5

Berry, A. (2017, December 21). Disability is the Poor Relation of Identity Politics. Disability Arts Online. https://disabilityarts.online/magazine/opinion/disability-poor-relation-identity-politics/ 


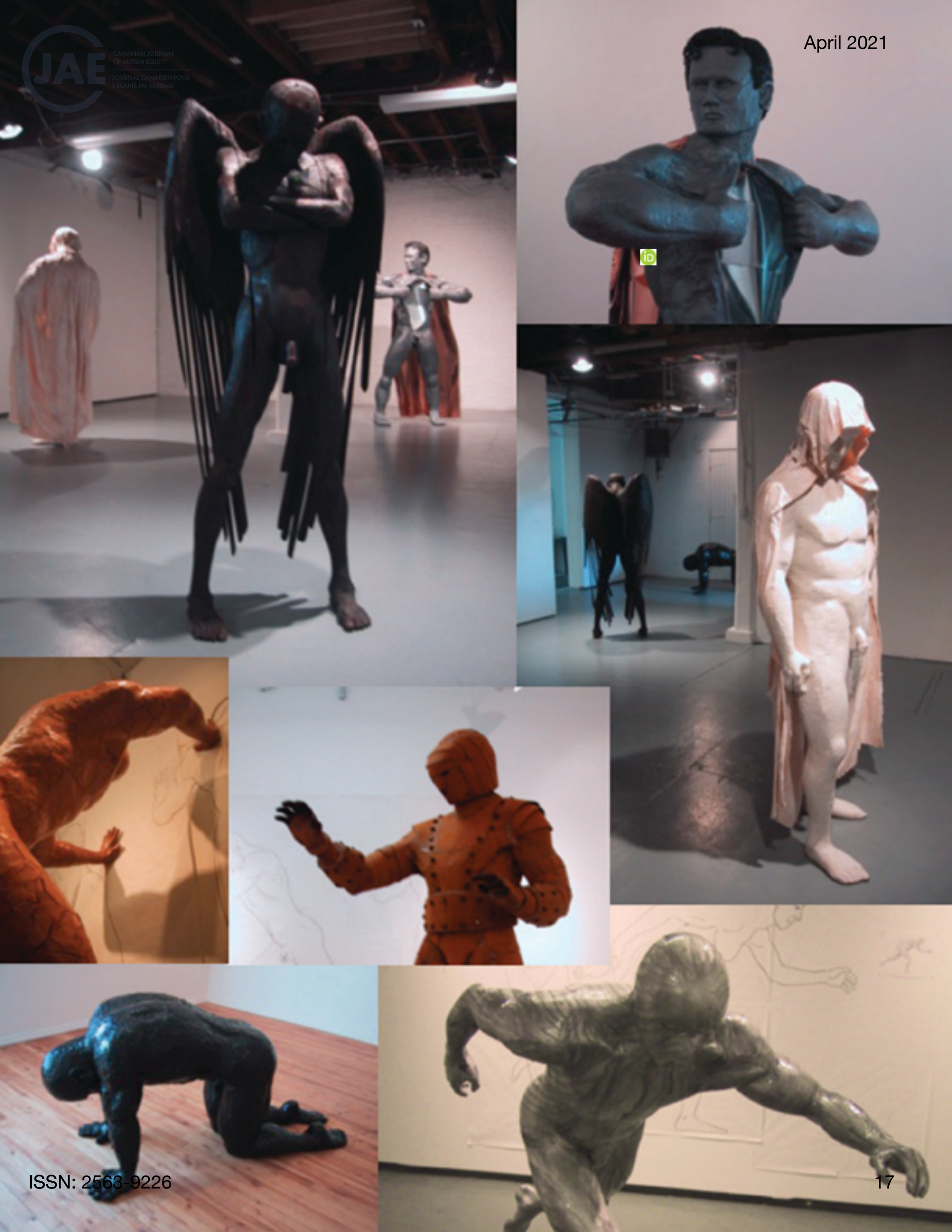

